УДК 662.7:662.763:662.765:621.311.22

\title{
ПАРОВАЯ БЕСКИСЛОРОДНАЯ ГАЗИФИКАЦИЯ В УСЛОВИЯХ ПОЛИГЕНЕРАЦИИ
}

\author{
Шевырёв Сергей Александрович ${ }^{1}$, \\ ssa.pmahp@kuzstu.ru
}

\section{Стрижак Павел Александрович²,} pavelspa@tpu.ru

Ральфр-Юве Дитрих ralph-uwe.dietrich@dlr.de

\section{Богомолов Александр Романович 4 , barom@kuzstu.ru}

1 Кузбасский государственный технический университет имени Т.Ф. Горбачева, Россия, 650000, г. Кемерово, ул. Весенняя, 28.

2 Национальный исследовательский Томский политехнический университет, Россия, 634050, г. Томск, пр. Ленина, 30.

3 Институт инженерной термодинамики, Германия, 70569, г. Штутгарт, Pfaffenwaldring, 38-40,

4 Институт теплофизики им. С.С. Кутателадзе СО РАН, Россия, 630090, г. Новосибирск, пр. Академика Лаврентьева, 1.

Актуальность исследования связана с перспективами глубокой переработки твердого топлива при нетрадиционном способе получения перегретого водяного пара в условиях тепловых электрических станций при осуществлении паровой бескислородной газифрикации. Это позволит создать на тепловых электрических станциях высокоэфрфективные энерготехнологические предприятия с производством не только тепловой и электрической энергии, но и разнообразных химических веществ, в частности водорода и продуктов синтеза Фишера-Тропша.

Цель: обосновать возможность и перспективы осуществления процесса паровой бескислородной газификации в условиях получения пара на тепловых электрических станциях в сравнении с широко применяемым процессом парокислородной газисиикации; сравнить процесс парокислородной и паровой бескислородной газифиикации по стоимости химических веществ, получаемых из синтез-газа в процессе синтеза Фишера-Тропша.

Объекты: процесс паровой бескислородной газисикации твердых топлив в условиях полигенерации; способ получения перегретого водяного пара на тепловых электростанциях для осуществления процесса паровой бескислородной газификации.

Методы: термодинамический анализ работы тепловых электрических станций с внутрицикловой газификацией; аналитический расчет процесса паровой бескислородной газисрикации и сравнение с проиессом парокислородной газисрикации; упрощенный расчет стоимости продуктов синтеза Фишера-Тропша при сравнении паровой бескислородной и парокислородной газификации.

Результаты. Представлена новая концепция полигенерации с использованием бескислородной паровой газисфикации в условиях получения пара на тепловых электрических станциях. Новая концепция полигенерации предполагает получение водяного пара с высокой температурой (до $1000{ }^{\circ} \mathrm{C}$ ) и давлением (до 2-3 МПа) для осуществления паровой бескислородной газифрикации твердых топлив. Концепция основана на термодинамическом обосновании работы тепловых электрических станций с традиционным паросиловым циклом и перераспределении материальных потоков между паровым котлом и паровой турбиной. Упрощенная экономическая оценка была сделана для расчета цены синтез-газа, получаемого в процессе паровой бескислородной газификации. Показано, что производство синтез-газа путем паровой бескислородной газификации в новой концепции может быть на 15 \% дешевле, чем при традиционной парокислородной технологии. Это может быть достигнуто при условии соотношения образующегося газа в процессе паровой бескислородной и парокислородной технологий более чем 3,5:1, соответственно.

Ключевые слова:

Высокотемпературный водяной пар, бескислородная газификация, возобновляемые ресурсы, полигенерация, синтез Фишера-Тропша.

\section{Номенклатура}

- $T$ - температура, ${ }^{\circ} \mathrm{C}$;

- $\quad$ - давление, Па;

- $\mathrm{S}$ - энтропия, кДж/(кг·К);

- $K$ - критическая точка для воды;

- $G_{e x}$ - расход питательной воды в паровой котел, $\kappa \Gamma / \mathrm{c}$;
- $G_{w v}$ - расход перегретого пара, поступающего из паровой турбины в паровой котел для дополнительного перегрева, кг/с;

- $\Delta H-$ тепловой эффект химической реакции, Дж/кг;

- $c_{a}$ - теплоемкость золы, кДж/(кг·К);

- $c_{c}$ - теплоемкость углерода, кДж/(кг·К);

- $c_{a a v}$ - средняя теплоемкость золы, кДж/(кг·К);

- $c_{c a v}-$ средняя теплоемкость углерода, кДж/(кг К К); 
- $c$ - теплоемкость углеродной частицы, кДж/(кг·К);

- $i_{s}$ - удельная энтальпия пара при соответствующем давлении и температуре, кДж/кг;

- $A^{d}$ - содержание золы углеродной частицы, \% мас.;

- $G_{s s}$ - расход перегретого пара для газификации, кг/с;

- $Q_{s s}$ - тепловой поток перегретого пара для газификации, Вт;

- $G_{g m}-$ расход газифицируемого материала в газогенераторе, кг/с;

- $G_{s t}-$ расход перегретого пара из паровой турбины для газификации, кг/с;

- $Q_{w}$ - тепловой поток для нагрева питательной воды, Вт;

- $i_{220}^{15.5}$ - энтальпия питательной воды при температуре $220^{\circ}$ Си давлении 15,5 МПа, кДж/кг;

$i_{10}^{0.1}$ - энтальпия питательной воды при температуре $10{ }^{\circ} \mathrm{Cи} \mathrm{давлении} 0,1 \mathrm{MПа,} \mathrm{кДж/кг;}$

- $Q_{s t}$ - тепловой поток, требуемый для перегрева пара, требуемого для газификации, Вт;

- $\boldsymbol{i}_{1000}^{2}$ - энтальпия перегретого пара при температуре $1000{ }^{\circ} \mathrm{C}$ и давлении 2 МПа, кДж/кг;

- $\boldsymbol{i}_{250}^{2}$ - энтальпия перегретого пара при температуре $250{ }^{\circ} \mathrm{C}$ и давлении 2 МПа, кДж/кг;

\section{Введение}

Технология газификации углеводородного сырья является одним из самых распространенных методов получения синтез-газа во всем мире. Известны исследования по газификации в различных окислительных, нейтральных и восстановительных средах при умеренных и высоких температурах. Достаточно подробно изучено влияние как характеристик исходного материала, так и условий протекания процесса газификации на выход и состав вырабатываемого синтез-газа [1].

Применение синтез-газа, получаемого в процессе газификации, осуществляется по двум направлениям: (i) в качестве топлива для энергетических установок паровые котлы, газовые турбины, двигатели внутреннего сгорания [2, 3]; (ii) в качестве исходного сырья для нетопливного применения с использованием различных технологий. Например, производство жидкого синтетического топлива по методу ФишераТропша [4].

Перспективным и наиболее востребованным направлением исследований остается получение синтез-газа для нетопливного применения при использовании его для производства жидких углеводородов, различных спиртов, смазочных материалов, различных эфиров и других веществ. Изучению этих процессов посвящено множество работ, направленных на исследование закономерностей и характеристик протекающих процессов для известных способов газификации.

Для нетопливного применения синтез-газ должен содержать как можно больше целевых компонентов в виде $\mathrm{CO}$ и $\mathrm{H}_{2}$. При этом объемное отношение целевых компонентов также должно составлять определенную величину для получения конкретного про-
- $Q_{\text {e.f. }}$ - теплотворная способность условного топлива, 29,308 МДж/кг;

- $G_{f}$ - расход топлива на подогрев питательной воды, $\mathrm{\kappa} \Gamma / \mathrm{c}$;

- $G_{b . f .}$ - дополнительный расход топлива в паровом котле, кг/с;

- $B_{u}$ - расход топлива в паровом котле, кг/c;

- $b_{u}$ - удельный расход условного топлива на выработку электрической энергии, г/(кВт·ч)

- $N_{e l}$ - мощность турбины, МВт;

- $Q_{\text {st.b }}$ - тепловая мощность парового котла, МВт;

- $q_{t u}$ - удельный расход тепловой энергии на выработку электрической энергии, МДж/(кВт·ч)

- $\eta_{p}$ - эффективность транспорта пара от котла к паровой турбине, \%;

- $\eta_{s t . b}$ - эффективность парового котла, \%;

- $\eta_{p s}-$ КПД тепловой электрической станции, \%;

- $V_{g}$ - формирование газа в идеальном процессе газификации, ${ }^{3} / \kappa г$;

- $Q_{L H V}$ - низшая теплотворная способность газа, МДж/кг;

- FT - синтез Фишера-Тропша;

- TEPET - Techno-Economic Process Evaluation Tool (инструмент технико-экономической оценки).

дукта. Например, если рассматривать получение жидких углеводородов по методу синтеза ФишераТропша соотношение CO: $\mathrm{H}_{2}=1: 2$ [4].

Получить наибольшее содержание $\mathrm{CO}$ и $\mathrm{H}_{2}$ в синтез-газе можно только в условиях парового бескислородного дутья в сравнении с различными газифицирующими агентами: воздух, кислород, вода и их смеси. Однако при этом имеется существенная проблема получения экономически эффективным способом большого количества водяного пара с высокой температурой (примерно до $1000-1200{ }^{\circ} \mathrm{C}$ ) и относительно высоким давлением (до 2-3 МПа).

Исследованиям паровой бескислородной газификации посвящено значительное количество работ в литературе. Как правило, процесс непосредственной паровой газификации проводят для частиц, предварительно прошедших термическую обработку [5]. Очень часто используют двухкамерные реакторы с кипящим слоем для экспериментального исследования паровой газификации [6]. Двухстадийность процесса во многих исследованиях позволяет для непосредственной газификации использовать частицы, состоящие из нелетучего углерода и золы. Это позволяет получить не только энергию для протекания процесса газификации (за счет сжигания летучих веществ), а также обеспечить достаточно высокое качество синтез-газа. Протекание процесса газификации в две стадии позволяет снизить расход перегретого пара, однако вместе с этим также значительно снижает образование целевых компонентов синтез-газа - СО и $\mathrm{H}_{2}$. При использовании в качестве газифицирующего агента только водяного пара, например, в обеих камерах двухстадийных газогенераторов требуется значительное количество пара. 
Большое количество водяного пара для эффективной реализации процесса газификации необходимо изза существенной эндотермичности химических реакций, протекающих в газогенераторе. Одним из целесообразных вариантов при настоящем уровне развития техники является получение перегретого водяного пара с заданными параметрами в условиях полигенерации [3]. Это можно осуществлять на тепловых электрических станциях, одновременно производящих тепловую и электрическую энергию, а также синтез-газ при паровой бескислородной газификации. Отсутствие кислорода крайне важно, так как это позволяет существенно сократить затраты на процесс газификации, в частности электрической энергии на получение кислорода, и таким образом значительно повысить экономическую привлекательность данного способа.

Существуют паровые котельные агрегаты, которые позволяют получать перегретый водяной пар до критических $\left(P<23 \mathrm{MПа,} T<560{ }^{\circ} \mathrm{C}\right)$ параметров для привода паровых турбин [7]. В топке таких паровых котлов температура дымовых газов существенно выше $1200{ }^{\circ} \mathrm{C}$, что позволяет осуществлять эффективный теплообмен между дымовыми газами и водяным паром. Благодаря такой высокой температуре также широко используется промежуточный перегрев водяного пара для уменьшения конечной влажности пара в последних ступенях паровой трубы и повышения КПД цикла [8].

Если осуществлять процесс промежуточного перегрева водяного пара не с целью уменьшения конечной влажности, а для повышения температуры при относительно невысоком давлении, то в этом случае можно получать большое количество высокотемпературного водяного пара для осуществления процесса паровой бескислородной газификации. Такая организация работы парового котла и паровой турбины может быть организована без значительного изменения конструкции парового котла и внедрена для большого класса не только крупных, но и средних по мощности энергетических станций. При незначительном давлении перегретого водяного пара, направляемого на паровую газификацию, отсутствует необходимость использования трубопроводы из высококачественных марок сталей, которые применяются при сверхкритических и ультрасверхкритических параметрах водяного пара [9].

В Российской Федерации существует государственный стандарт ГОСТ 5632-2014 [10]. В нем описаны различные материалы и сплавы, которые могут быть применимы для температуры менее $1000{ }^{\circ} \mathrm{C}$ и давления менее 30 бар. При этом срок службы данных материалов может варьироваться от 1 года и более в зависимости от температуры пара. Например, если температура пара в дополнительном парогенераторе будет около $850{ }^{\circ} \mathrm{C}$, то его ожидаемый срок службы может составлять около 11 лет. В научной литературе представлены работы по паровой конверсии метана, например $[11,12]$. В некоторых из них показаны различные материалы и сплавы, которые применяются в том числе и как катализаторы при температуре до $900{ }^{\circ} \mathrm{C}$ и давлении до 15 бар.
Цель настоящей работы - термодинамическое обоснование перспектив производства в условиях полигенерации высокотемпературного водяного пара среднего давления, используемого для осуществления процесса паровой бескислородной газификации, оценка его стоимости и сравнение с известными технологиями.

\section{Методология}

Принципиальная схема производства высокотемпературного водяного пара в условиях полигенерации включает несколько необходимых элементов (рис. 1). Они взаимодействуют друг с другом и позволяют получать тепловую, электрическую энергию и перегретый водяной пар для осуществления паровой бескислородной газификации различного исходного сырья, например биомассы, угля или твердых бытовых отходов.

Центральным элементом схемы является паровой котел - 1. Его основной задачей является получение тепловой энергии в виде перегретого водяного пара с высоким давлением и температурой $\left(P_{0}, T_{0}\right)$ для подачи в паровую турбину -2 . В паровой турбине должен быть предусмотрен регулируемый отбор водяного пара с более низкими параметрами $\left(P_{1}, T_{1}\right)$.

Отработавший пар из турбины (с параметрами $P_{1}$, $T_{1}$ ) поступает в котел, где он снова перегревается до высокой температуры $\left(P_{1}, T_{2}\right)$ при осуществлении изобарного процесса. Температура перегрева $T_{2}$ водяного пара зависит от характеристик котла, условий теплообмена в топке котла. При расположении дополнительного пароперегревателя в радиационной части котла, где температура дымовых газов имеет максимальную температуру, можно ожидать температуру перегрева водяного пара более $900{ }^{\circ} \mathrm{C}$ при требуемом давлении не более 2-3 МПа. Эти параметры вторичного перегрева водяного пара могут быть достигнуты при использовании широкой номенклатуры котельных агрегатов, работающих на различных видах топлива.

В соответствии с предлагаемой схемой организации процесса получения перегретого водяного пара (рис. 1) паровая бескислородная газификация может быть осуществлена при использовании принципиально разных по назначению турбин (рис. 2). Так, например, при необходимости получения тепловой энергии для снабжения сторонних потребителей может быть применена теплофикационная турбина. При отсутствии потребителей можно применять турбину с противодавлением, на выходе из которой отработавший водяной пар подается сразу в котел. После дополнительного перегрева водяной пар поступает на паровую газификацию.

После перегрева в котле водяной пар поступает в редукционную установку - 6 (рис. 1), где его давление и температура при необходимости уменьшаются. Далее водяной пар поступает в газификатор и аппарат пиролиза. Последний может быть использован для предварительной газификации исходного материала с целью получения коксового остатка и парогазовой смеси. 


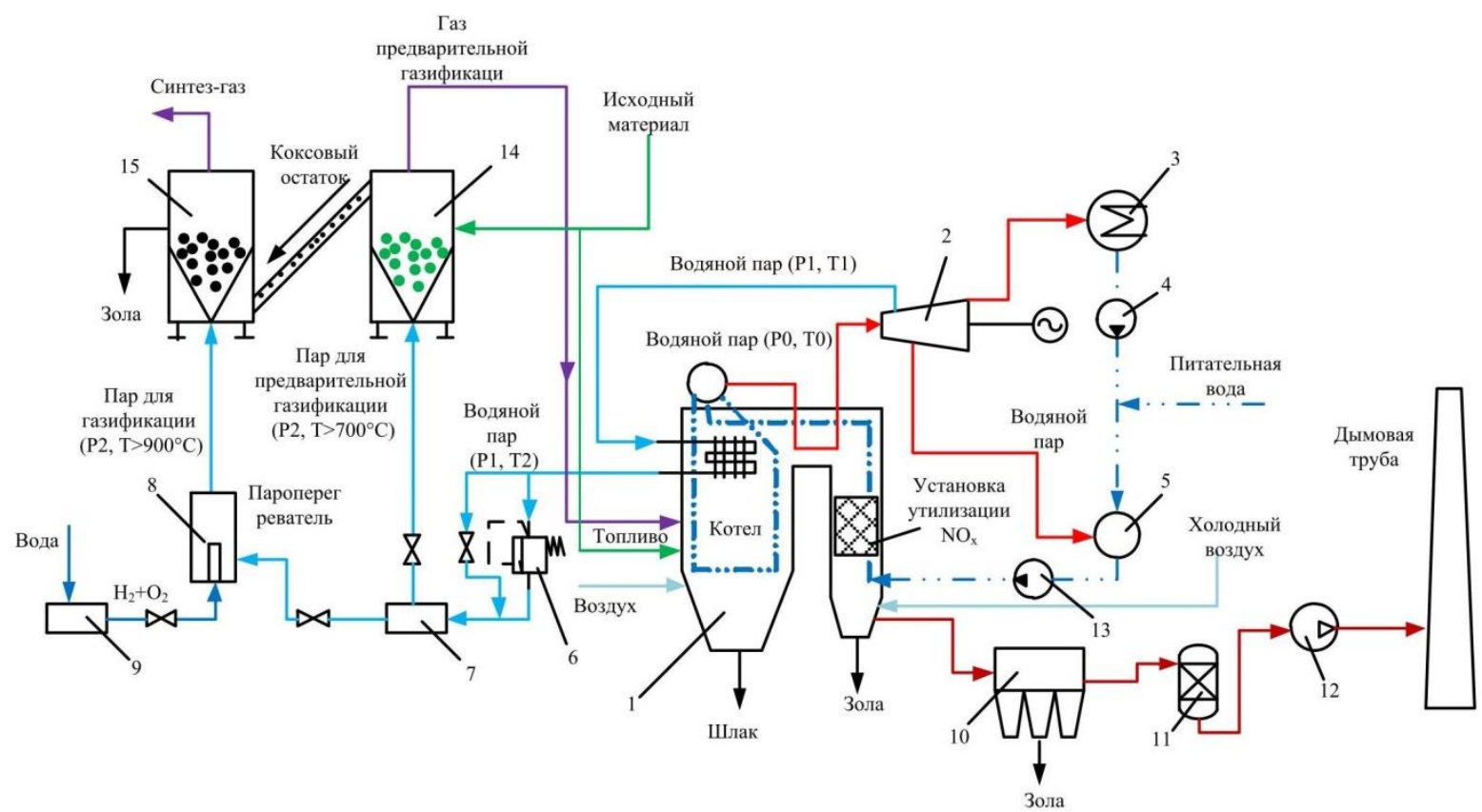

Рис. 1. Принципиальная схема полигенерации в условиях конденсационной электрической станции: 1 - паровой котел; 2 - паровая турбина с регулируемым отбором пара; 3 - конденсатор; 4 - питательный насос; 5 - регенеративный теплообменник; 6 - редукиионная установка; 7 - делитель потоков; 8 - кислородно-водородный пароперегреватель; 9 - электролизная установка; 10 - электрофильтр; 11 - сероочистка; 12 - дымосос; 13 - насос высокого давления; 14 - аппарат пиролиза исходного материала; 15 - газификатор

Fig. 1. Schematic diagram of polygeneration in a condensing power station: 1 - steam boiler; 2 - steam turbine with adjustable extraction of steam; 3 -condenser; 4 -feed pump; 5 - regenerative heat exchanger; 6 - reduction unit; 7 - stream divider; 8 - oxygen-hydrogen superheater; 9 - electrolysis unit; 10 - electrostatic precipitator; 11 desulfurization; 12 - exhauster; 13 - high pressure pump; 14 - apparatus for pyrolysis of the source material; 15 gasifier

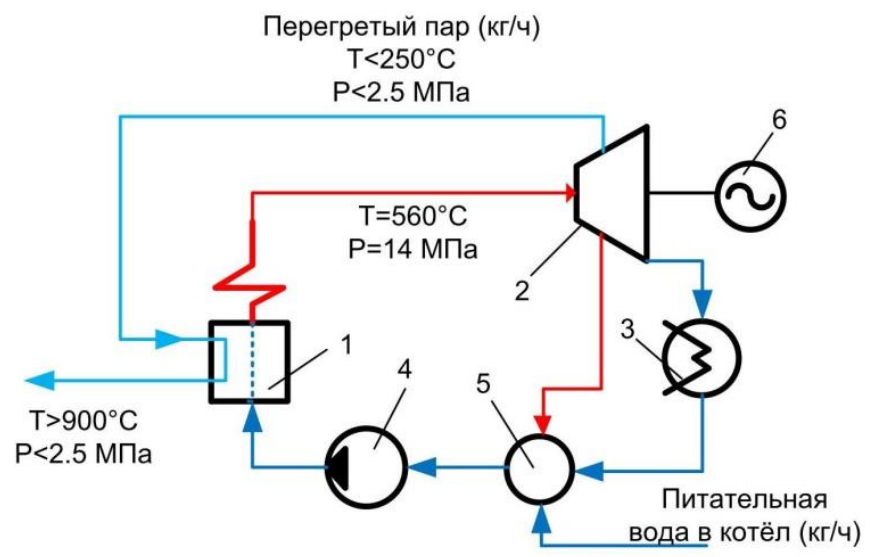

a)

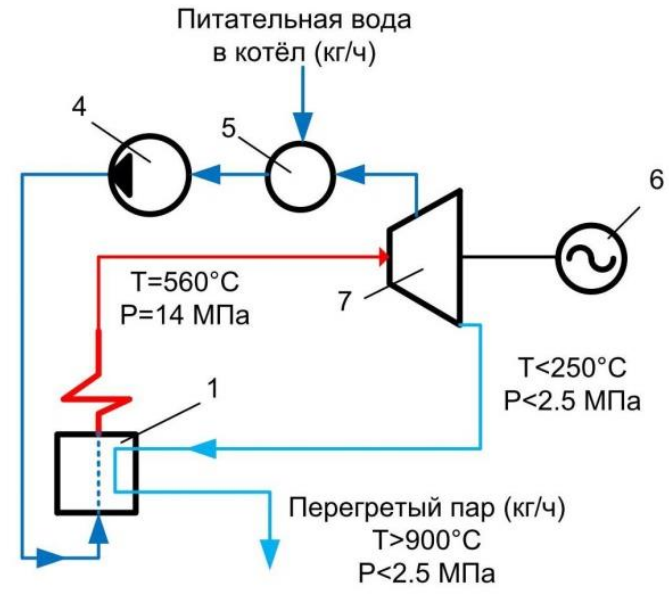

b)

Рис. 2. Принципильные схемы получения перегретого водяного пара: а) при использовании конденсационной турбины; b) при использовании турбины с противодавлением. 1 - паровой котел; 2 - конденсационная или теплофикационная турбина; 3 - конденсатор; 4 - насос; 5 - регенеративный теплообменник; 6 - электрогенератор; 7 - турбина с противодавлением

Fig. 2. Principle diagrams of superheated steam generation: a) using a condensing turbine; $b$ ) using a back pressure turbine. 1 - steam boiler; 2 - condensation or cogeneration turbine; 3 - condenser; 4 - pump; 5 - regenerative heat exchanger; 6 -electric generator; 7 - back pressure turbine

Применение аппарата пиролиза имеет следующие преимущества. Большинство соединений таких элементов, как $\mathrm{N}, \mathrm{S}, \mathrm{C}$ и других (например, $\mathrm{SO}_{\mathrm{x}}, \mathrm{NO}_{\mathrm{x}}$, $\mathrm{CO}_{2}$ ), после аппарата пиролиза вместе с паром (паро- водяная смесь) поступают в паровой котел. Некоторые из них относительно безвредны, а некоторые нет (например, смолы). Вредные соединения окисляются в котле и попадают в систему очистки (различные 
фильтры): $\mathrm{SO}_{x}, \mathrm{NO}_{\text {х }}$ и другие. Далее в виде дымового газа поступают в дымовую трубу и рассеиваются.

Коксовый остаток при этом используется в газификаторе для осуществления основного процесса газификации, а парогазовая смесь (водяной генераторный газ), полученная при частичной газификации, может, например, подаваться в котел для сжигания. Организация процесса по указанной схеме позволяет получить дополнительное топливо для сжигания в котле, при частичном замещении основного топлива. Карбонизат, который используется для основного процесса газификации, позволяет значительно улучшить гидродинамический режим в газификаторе, а также получить синтез-газ высокого качества. Такая схема организации процесса может быть востребована при газификации, например, низкокачественного угля (отходы угледобычи) или твердых бытовых отходов.

Разделение процесса на предварительный пиролиз и газификацию дает очень чистый синтез-газ с минимальным количеством балластных примесей. Все летучие вещества и другие балластные примеси, например смолы, во время предварительной газификации попадают в топку котла, где полностью выгорают при высокой температуре. Таким образом, одновременно решается два вопроса: повышение качества синтезгаза, что впоследствии влияет на очистку и синтез химических веществ, а также повышение экологичности и эффективности утилизации вредных веществ при горении. Экологичность и эффективность достигается за счет того, что в котельных агрегатах предусмотрены системы очистки дымового газа, которые позволяют, например, нейтрализовать оксиды серы.

В случае, если не удается получить перегретый водяной пар приемлемых параметров по температуре в котле, в схеме должен быть предусмотрен дополнительный пароперегреватель -8 (рис. 1). В этом случае перегретый пар после редукционной установки подается непосредственно в пароперегреватель [13].

Пароперегреватель представляет собой камеру, в которой имеется специальная газовая горелка. В горелку поступает стехиометрическая кислородноводородная смесь [13] и сжигается в потоке водяного пара, поступающего из котла [14]. Продуктами сгорания кислородно-водородной смеси является водяной пар с незначительным (менее $0,5 \%$ об.) количеством неконденсируемых газов. Кислородно-водородная смесь образуется электролизом или другим известным способом, который позволяет с наименьшими затратами получать необходимое количество смеси для осуществления перегрева водяного пара до требуемой температуры. Регулируя балансовые соотношения продуктов горения кислородно-водородной смеси и перегретого водяного пара, поступающего из котла, можно получать на выходе из пароперегревателя температуру пара, изменяющуюся в широком диапазоне.

Кислородно-водородный пароперегреватель может и не использоваться в качестве одного из основных элементов схемы. Однако в качестве резервного элемента он должен быть предусмотрен. Его использование оказывает влияние на параметры (например, температуру) перегретого водяного пара, поступающего в газогенератор - 15 (рис. 1), и, соответственно, на качественный состав получаемого синтез-газа [1]. Результаты исследований [15] показывают, что при повышении температуры водяного пара более $900{ }^{\circ} \mathrm{C}$ практически исключается содержание смолистых соединений в синтез-газе. Поэтому при необходимости значительного повышения температуры перегретого пара использование пароперегревателя допустимо. В этом случае существенное значение имеют плавкостные характеристики золы [6] газифицируемого материала, которые совместно с конструкцией газогенератора определяют максимальную температуру в газогенераторе. Когда температура золы очень высока, она плавится (зависит от сырья). Таким образом изменяются физические свойства и химический состав золы, что может нарушать нормальную работу газогенератора.

\section{Результаты и обсуждение}

Энергетические характеристики производства перегретого пара

Термодинамический цикл (рис. 2, а) предлагаемого процесса (рис. 1) представлен на $T-S$ диаграмме (рис. 3). Черная линия изображает идеальный термодинамический цикл Ренкина 1234561, включающий элементы: паровой котел с пароперегревателем - 1 (рис. 1), паровая турбина с конденсатором $-2,3$ (рис. 1), а также питательные насосы - 4, 13 (рис. 1). Дополнительно на диаграмме обозначены точки 1,7 и 8 , которые соответствуют процессу производства перегретого водяного пара (для газификации) в паровом котле. В точке 7 происходит отбор перегретого водяного пара из турбины с параметрами $P_{1}, T_{1}$, который далее поступает в котельный агрегат. При этом количество отобранного пара из турбины компенсируется дополнительной подпиткой воды в точке 1 перед насосом высокого давления - 13 (рис. 1) до повышения давления воды, поступающей в котел. Перегрев отработавшего пара в турбине осуществляется в котле от параметров $P_{1}, T_{1}$ до параметров $P_{1}, T_{2}$ - точки 7 , 8 , при осуществлении изобарного процесса. Необходимое количество теплоты при этом подводится за счет сжигания дополнительного количества топлива в котле. Процесс 7, 8 по своей сути аналогичен процессу работы турбины с перегревом пара.

Для проектируемых тепловых электрических станций дополнительный отбор пара из турбины для газификации должен быть заранее предусмотрен в соответствии с тепловой мощностью потока пара вторичного перегрева и проектной мощностью газогенератора.

В соответствии со схемой предлагаемого процесса (рис. 1), перегретым водяным паром может быть осуществлена предварительная газификация исходного материала. В этом процессе происходит частичная газификация исходного материала за счет вноса теплоты с водяным паром.

При частичной паровой газификации тепловые затраты (расход пара) существенно зависят от характеристик исходного материала, степени предваритель- 
ной газификации, условий процесса и других параметров. Например, если исходный материал значительно увлажнен, то требуется дополнительное количество пара для его предварительной сушки. С другой стороны, в случае древесной биомассы или сельскохозяйственной биомассы следует использовать разное количество перегретого водяного пара для получения коксовых частиц.

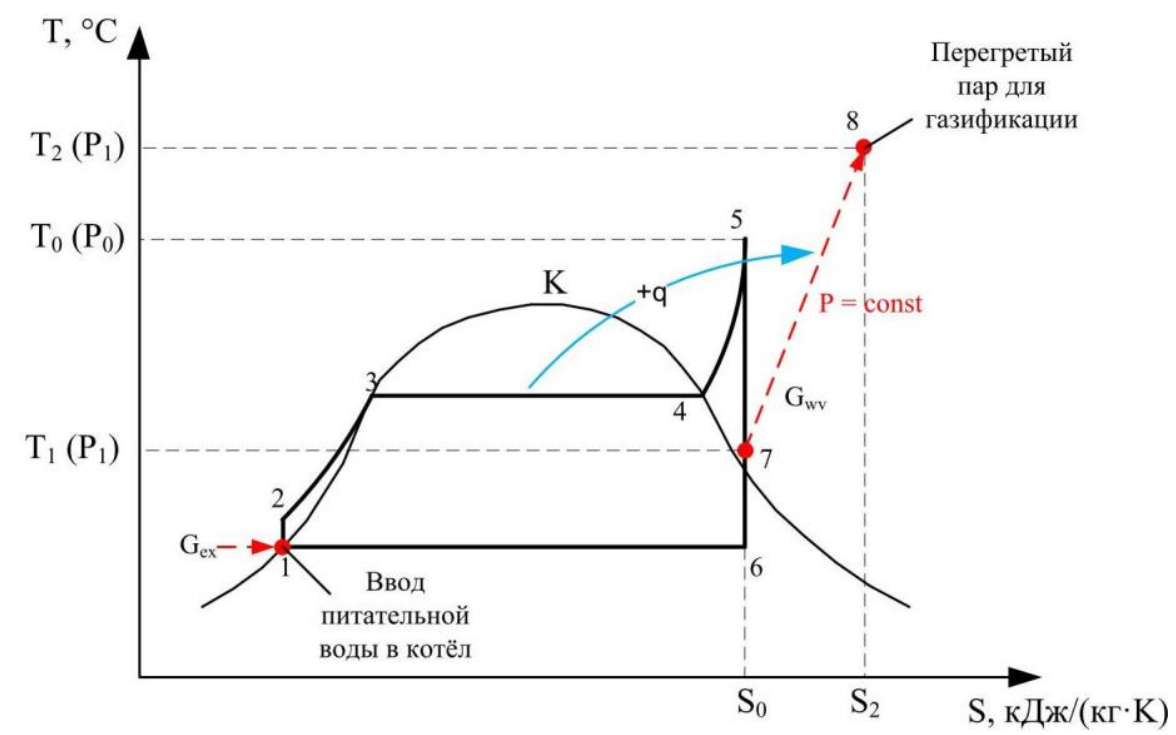

Pис. 3. Условная $T-S$ диаграмма паросилового ичикла с перегревом водяного пара для газификации. $G_{e x}, G_{w v}-$ равные расходы питательной воды и водяного пара соответственно; $K-$ критическая точка для воды; $+q-$ подвод тепловой энергии к водяному пару за счет сжсиания топлива в паровом котле

Fig. 3. Conditional T-S steam power cycle diagram with steam superheating for gasification. $G_{e x}, G_{w v}-$ feed water and water vapor flow rates, respectively; $K$-critical point for water; $+q-$ thermal energy supply to water vapor due to fuel combustion in the steam boiler

Аналитическая оценка затрат тепловой энергии, поступающей в аппарат пиролиза с перегретым водяным паром, в данном случае крайне затруднительна [16]. Попытка оценки этих параметров приводит к значительному числу допущений и всегда носит приблизительный характер.

Только натурные эксперименты на исходном газифицируемом материале позволяют оценить тепловые затраты на газификацию в этом случае. Среди работ других авторов можно отметить [17], в которой была предпринята оценка тепловых затрат на осуществление процесса пиролиза шламов сточных вод различного происхождения. В данной работе при нагреве с постоянной скоростью влажных образцов было установлено, что некоторые виды отходов могут характеризоваться самоподдерживающимся процессом при сравнении тепловых затрат на пиролиз и теплоты, полученной при сжигании пиролизного газа. Это зависит от количества горючих компонентов, формирующихся в процессе пиролиза, и их теплотворной способности.

При осуществлении каскадного процесса пиролиза и паровой газификации биомассы или других веществ, как предлагается на рис. 1, в аппарате пиролиза образуется коксовые частицы и парогазовая смесь. Коксовые частицы далее используются в газогенераторе 15 (рис. 1), а парогазовая смесь может подаваться на сжигание в паровой котел - 1 (рис. 1). В этом случае в работе котла может наблюдаться улучшение характеристик, например, по количеству выбрасываемых вредных веществ в атмосферу $\left(\mathrm{SO}_{\mathrm{x}}, \mathrm{NO}_{\mathrm{x}}\right)$ : (i) за счет совместного сжигания твердого топлива и газа [7]; (ii) за счет горения и частичной газификации, аналогичной сжиганию водоугольного топлива [18], при поступлении относительно большого количества водяного пара в топку котла.

В процессе паровой газификации коксовых частиц в газогенераторе - 15 (рис. 1) основная химическая реакция может быть представлена следующим обра30м:

$$
\mathrm{C}+\mathrm{H}_{2} \mathrm{O}=\mathrm{CO}+\mathrm{H}_{2}-10,94 \mathrm{MДж/кг.}
$$

В этом случае можно принять поступление в газификатор частиц, состоящих только из углерода и инертного зольного остатка. В лабораторных условиях при паровой бескислородной газификации для угольных образцов может формироваться до 90 \% целевых компонентов $\left(\mathrm{CO}\right.$ и $\left.\mathrm{H}_{2}\right)$ в составе синтез-газа [19]. Поэтому реакция (1) может быть принята для предварительной оценки существа предлагаемого процесса. В целом реакция (1) отражает протекание процесса паровой бескислородной реакции. И в данном случае далее считается, что частицы (char particles) состоят только из углерода и золы. В этом случае совершенно не важно, какой исходный материал (биомасса) может быть использован для газификации.

Тепловой эффект эндотермической реакции (1) составляет $\Delta H=10,94$ МДж/кг [20]. Данный тепловой эффект реакции соответствует параметрам протекания реакции при температуре $25^{\circ} \mathrm{C}$ и давлении около 0,1 МПа. В большинстве случаев газификация 
протекает при температурах в газогенераторе $700-1000{ }^{\circ} \mathrm{C}$ [21]. При таких температурах тепловой эффект реакции практически не меняется и увеличивается от стандартного теплового эффекта реакции примерно на 3,5 \% (за счет изменения теплоемкости веществ, участвующих в реакции) в соответствии с законом Гесса и Кирхгофа. Поэтому в реакции (1) для дальнейших расчетов можно принять тепловой эффект в диапазоне температур $700-1000{ }^{\circ} \mathrm{C} \Delta H=11,3$ МДж/кг.

В реакции (1) участвует только углерод и водяной пар. В реальных условиях при газификации твердых материалов в газифицируемой частице всегда присутствуют минеральные компоненты, доля которых зависит от качества исходного топлива. На нагрев коксовых частиц до необходимой температуры (примем $\left.700{ }^{\circ} \mathrm{C}\right)$ в реакции (1) затрачивается тепловая энергия, поступающая вместе с паром при аллотермической газификации [6]. Теплоемкость таких коксовых частиц изменяется в зависимости от процентного содержания углерода и золы $([22,23])$. Теплоемкость золы и углерода может быть вычислена соответственно:

$$
\begin{gathered}
\left.c_{a}=0,8+0,51 \cdot 10^{-3} t-0,13 \cdot 10^{-6} t^{2} \text { кДж/(кг } \cdot \mathrm{K}\right)[22], \\
c_{c}=0,93+0,913 \cdot 10^{-3} t-0,41 \cdot 10^{-5} t^{2} \text { кДж/(кг К К) [23]. }
\end{gathered}
$$

В диапазоне температур от 700 до $1100{ }^{\circ} \mathrm{C}$ теплоемкость углерода и кокса составляет (табл. 1):

Таблица 1. Теплоемкость углерода и зольного остатка

\begin{tabular}{|c|c|c|c|c|c|}
\hline \multirow{2}{*}{$\begin{array}{l}\text { Удельная теплоемкость } \\
\text { Specific heat capacity }\end{array}$} & \multicolumn{5}{|c|}{$\begin{array}{c}\text { Температура } \\
\text { Temperature, }{ }^{\circ} \mathrm{C}\end{array}$} \\
\hline & 700 & 800 & 900 & 1000 & 1100 \\
\hline$c_{a}, \mathrm{\kappa Д} /(\kappa \Gamma \cdot \mathrm{K}) / \mathrm{kJ} /(\mathrm{kg} \cdot \mathrm{K})$ & 1,09 & 1,12 & 1,15 & 1,18 & 1,20 \\
\hline$c_{\text {aav }}$, средн./average & \multicolumn{5}{|c|}{1.15} \\
\hline$c_{c}, \mathrm{\kappa Д} /(\kappa \Gamma \cdot \mathrm{K}) / \mathrm{kJ} /(\mathrm{kg} \cdot \mathrm{K})$ & 1,49 & 1,60 & 1,70 & 1,80 & 1,90 \\
\hline$c_{c a v}$, средн./average & \multicolumn{5}{|c|}{1,7} \\
\hline
\end{tabular}
Table 1. Specific heat capacity of carbon and ash residue

Теплоемкость коксовой частицы может быть вычислена по выражению [22]:

$$
c=\frac{c_{a} \cdot m_{a}+c_{c} \cdot m_{c}}{m}
$$

где $m_{a}, m_{c}-$ массовая доля золы и углерода в частице соответственно; $m$ - масса частицы.

В диапазоне зольности от 10 до 70 \% теплоемкость частицы, при усреднении данных в табл. 1, может быть принята $c=1,37$ кДж/(кг·К).

В зависимости от типа и мощности паровой турбины расход водяного пара для ее привода может существенно изменяться. Это, в свою очередь, влияет на количество пара, отбираемого на технологические нужды и, в частности, для рассматриваемого примера - на осуществление процесса паровой бескислородной газификации. Рассчитаем удельные энергозатраты на осуществление процесса газификации для 1 кг коксовых частиц.

В результате протекания реакции (1) в соответствии со стехиометрией количество водяного пара, участвующего в реакции, составляет 1,5 кг на 1 кг углерода.
Примем для расчета следующие характеристики водяного пара: температура $T_{1}=1000{ }^{\circ} \mathrm{C}$ и давление $P_{2}=2$ МПа. При данных параметрах энтальпия пара составляет $i_{\mathrm{s}}=4637$ кДж/кг.

Суммарные затраты перегретого водяного пара могут быть приняты как сумма теплоты: (i) на нагрев частицы с 700 до $1000{ }^{\circ} \mathrm{C}$; (ii) компенсация теплового эффекта реакции (1); (iii) протекание реакции (1) при взаимодействии углерода кокса и перегретого пара.

Для принятых допущений суммарный расход пара для частиц с зольностью от 10 до 70 \% в пересчете на 1 кг реагирующего исходного материала должен составлять величины, представленные в табл. 2. Данные в табл. 2 также учитывают потери теплоты в газогенераторе, которые приняты в размере $3 \%$ от общего теплопоступления.

Таблица 2. Суммарный расход пара (теплоты) на осуществление паровой газификации коксовых частии

Table 2. Total steam consumption (heat) for steam gasification of carbon particles

\begin{tabular}{|c|c|c|c|c|c|c|c|}
\hline Суммарный расход & \multicolumn{6}{|c|}{$A^{d}$, Зольность коксовой частицы, \% мас. } \\
$\begin{array}{c}\text { перегретого пара (теп- } \\
\text { лоты), кг (МДж) }\end{array}$ & \multicolumn{7}{|c|}{$A^{d}$, char ash content, \% wt. } \\
\cline { 2 - 8 } $\begin{array}{c}\text { Total superheated steam } \\
\text { consumption } \\
\text { (heat), kg/s (MJ) }\end{array}$ & 10 & 20 & 30 & 40 & 50 & 60 & 70 \\
\hline$G_{s s}$, кг/c/kg/s & 3,74 & 3,34 & 2,93 & 2,52 & 2,12 & 1,71 & 1,31 \\
\hline$Q_{s s}$, МДж/MJ & 17,35 & 15,47 & 13,59 & 11,71 & 9,82 & 7,94 & 6,06 \\
\hline
\end{tabular}

В табл. $2 G_{s s}$ составляет расход пара на 1 кг газифицируемого материала с различным содержанием минеральных примесей (в соответствии с реакцией (1)).

В схеме на рис. 1 основным элементом является паровой котел. От его характеристик зависит расход перегретого пара на парообразование и характеристики перегретого водяного пара, поступающего на вход в паровую турбину. Причем наиболее важным параметром в данном случае является температура перегретого водяного пара. Для большинства котельных агрегатов, работающих в докритической области, температура перегретого водяного пара может быть принята до $560{ }^{\circ} \mathrm{C}$ [24]. При данной температуре и давлении 14 МПа расход перегретого пара на турбину (с параметрами $P_{0}, T_{0}$ ) при средней тепловой мощности котельного агрегата 400 МВт составляет около 115 кг/с пара.

В случае совместной работы котла с паровой турбиной с противодавлением (рис. 2, b) значительная часть перегретого водяного пара на выходе из турбины может быть направлена обратно в котельный агрегат. В этом случае необходимо предварительно знать количество перегретого пара, которое поступает из отборов турбины на регенеративный подогрев питательной воды.

В случае использования конденсационной или теплофикационной турбины (рис. 2, а) количество перегретого водяного пара на отбор турбины существенно зависит от вида применяемой турбины. При проектировании турбоагрегатов отбор перегретого 
водяного пара на технологические нужды заранее определен техническим заданием, поэтому он может изменяться в широких пределах.

Для оценки расхода перегретого водяного пара, необходимого для осуществления процесса газификации, примем величину отбора в соответствии с усредненными характеристиками паровых турбин. Во многих существующих энергетических установках расход перегретого водяного пара на промышленные нужды составляет до 25-30 \% от количества свежего пара на входе в турбину. Следовательно, максимальный отбор перегретого водяного пара из турбины в примере расчета настоящей работы составляет не более $G_{s t}=34,5$ кг/с. При таком расходе и ранее определенном количестве перегретого водяного пара (табл. 2), требуемого для газификации 1 кг исходного топлива, расход газифицируемого материала в газогенераторе составляет (табл. 3):

Таблица 3. Расход газифицируемого материала в газогенераторе

Table 3. Consumption of gasified material in the gas generator

\begin{tabular}{|c|c|c|c|c|c|c|c|}
\hline Расход газифицируе- & \multicolumn{7}{|c|}{$A^{d}$, Зольность коксовой частицы, \% мас. } \\
$\begin{array}{c}\text { мого материала } \\
\text { Consumption of gasified } \\
\text { material, kg }\end{array}$ & 10 & 20 & 30 & 40 & 50 & 60 & 70 \\
\hline$G_{g m}, \mathrm{\kappa r} / \mathrm{c} / \mathrm{kg} / \mathrm{s}$ & 9,50 & 10,65 & 12,13 & 14,08 & 16,77 & 20,74 & 27,17 \\
\hline
\end{tabular}

Для современных тепловых электрических станций средний удельный расход топлива относительно выработки электрической энергии в котельном агрегате составляет около $b_{u}=280$ г.у.т./кВт·ч $([25,26])$. Данный расход топлива соответствует тепловой электрической станции уже с учетом отборов пара из турбины на регенеративный подогрев питательной воды, но без учета количества перегретого пара, который может быть отобран на паровую газификацию.

При организации процесса дополнительного перегрева водяного пара для осуществления процесса газификации потребуется дополнительное количество тепловой энергии. Это количество тепловой энергии будет получено за счет увеличения количества сжигаемого топлива в топке котла. Таким топливом будет являться либо проектное топливо для соответствующего котельного агрегата, либо горючие летучие вещества, образующиеся при пиролизе газифицируемого сырья (рис. 1). Так как часть перегретого водяного пара отбирается безвозвратно из котельного агрегата, то для восполнения этого количества воды должна увеличиваться подпитка в котел. При этом теплота сжигаемого топлива должна затрачиваться на подогрев воды от температуры, при которой вода поступает при температуре окружающей среды (примем температуру $\left.10{ }^{\circ} \mathrm{C}\right)$, до температуры перегретого водяного пара, то есть до $560{ }^{\circ} \mathrm{C}$. Тогда расход теплоты на подогрев питательной воды, поступающей в котел, составит:

$$
\begin{gathered}
Q_{w}=G_{s t}\left(i_{220}^{15.5}-i_{10}^{0.1}\right)= \\
=34,5 \cdot(947,66-42,11) \cdot 10^{3}=31,2 \cdot 10^{6} \text { Вт. }
\end{gathered}
$$

Дополнительное количество топлива необходимо затратить на перегрев водяного пара в котельном агрегате. Для ранее принятых параметров это количество теплоты составит:

$$
\begin{gathered}
Q_{s t}=G\left(i_{1000}^{2}-i_{250}^{2}\right)= \\
=34,5 \cdot(4637-2903,23) \cdot 10^{3}=59,82 \cdot 10^{6} \mathrm{BT} .
\end{gathered}
$$

Нагрев питательный воды может быть осуществлен в отдельно стоящем водогрейном котле при невозможности повышенного отбора пара из турбины на регенеративный подогрев питательной воды. Либо при использовании более мощной паровой турбины (рис. 1) при таком же или меньшем отборе пара из турбины при неизменных характеристиках по электрической мощности.

Дополнительный расход топлива на подогрев питательный воды $Q_{w}$ с учетом теплоты сгорания условного топлива составит:

$$
G_{f}=\frac{Q_{w}}{Q_{e . f}}=\frac{31,2 \cdot 10^{6}}{29,308 \cdot 10^{6}}=1,06 \kappa \Gamma / \mathrm{c} .
$$

При этом может быть использовано любое топливо для подогрева питательной воды, а также любые нетрадиционные источники тепловой энергии, например солнечные электростанции [27, 28].

Получение тепловой энергии для перегрева водяного пара $Q_{s t}$ в паровом котле - 1 (рис. 1) может быть осуществлено: (i) за счет увеличения расхода топлива, на которое спроектирован паровой котел; (ii) за счет совместного сжигания проектного топлива и газа, образующего при частичной газификации исходного материала в аппарате пиролиза - 14 (рис. 1).

С учетом теплоты сгорания условного топлива дополнительный расход его в паровом котле составит:

$$
G_{b . f}=\frac{Q_{s t}}{Q_{e . f}}=\frac{59,82 \cdot 10^{6}}{29,308 \cdot 10^{6}}=2,04 \mathrm{\kappa г} / \mathrm{c} .
$$

При заданном удельном расходе топлива $b_{u}=280$ г.у.т./кВт·ч общий КПД электростанции может быть вычислен (для условного топлива с теплотой сгорания 29,308 МДж/кг):

$$
\eta_{p s}=\frac{123}{b_{u}}=\frac{123}{280}=0,44 .
$$

Удельный расход теплоты (перегретого пара) на выработку электрической энергии может быть вычислен:

$$
q_{t u}=\frac{3600 \cdot \eta_{p} \cdot \eta_{s t . b}}{\eta_{p s}}=7216,36 \kappa \text { КЖ } /(\kappa В \mathrm{~T} \cdot ч),
$$

где $\eta_{p}-$ КПД транспорта пара от котла к паровой турбине, \% (принято 98 \%); $\eta_{s t . b}$ - КПД парового котла, \% (принято $90 \%$ ).

Электрическая мощность турбины может быть рассчитана следующим образом:

$$
N_{e l}=\frac{Q_{s t . b}}{q_{t u}}=\frac{1,44 \cdot 10^{9}}{7216,36}=199,5 \mathrm{MBT},
$$

где $Q_{s t . b}$ - тепловая нагрузка (мощность) парового котла, MW, принятая 400 MBт, или $1,44 \cdot 10^{9}$ кДж/ч. 
Действительный расход условного топлива в паровом котле может быть рассчитан следующим образом:

$$
B_{u}={ }_{b u} \cdot N_{e l}=15,5 \text { кг } / \mathrm{c} .
$$

Зная вышеопределенные дополнительные расходы топлива на подогрев питательной воды $G_{f}$ и на дополнительный перегрев водяного пара в котле $G_{b . f f}$, можно оценить изменение удельного расхода условного топлива на выработку электрической энергии $b_{u}$, которое составит 316,5 г/(кВт·ч) и 335,6 г/(кВт·ч) соответственно:

$$
\begin{gathered}
B=B_{u}+G_{b . f}=15,5+2,04=17,54 \mathrm{\kappa} / \mathrm{c}, \\
b_{u}=\frac{B}{N_{e l}}=\frac{17,54 \cdot 10^{-3} \cdot 3600}{199,5 \cdot 10^{6}}=316,5 \Gamma /\left(\mathrm{KBT}_{\mathrm{e}} \cdot \mathrm{ч}\right) .
\end{gathered}
$$

С учетом теплоты нагрева питательной воды, поступающей в котел:

$$
\begin{gathered}
G_{b . f}=\frac{Q_{s t}+Q_{w}}{Q_{e . f}}=\frac{59,82 \cdot 10^{6}+31,2 \cdot 10^{6}}{29,308 \cdot 10^{6}}=3,1 \mathrm{\kappa} / \mathrm{c}, \\
B=B_{u}+G_{b . f}=15,5+3,1=18,6 \mathrm{\kappa} / \mathrm{c}, \\
b_{u}=\frac{B}{N_{e l}}=\frac{18,6 \cdot 10^{-3} \cdot 3600}{199,5 \cdot 10^{6}}=335,6 \Gamma /\left(\mathrm{\kappa BT}_{\mathrm{e}} \cdot \mathrm{ч}\right) .
\end{gathered}
$$

Полученные результаты на 13 и 19,6 \% больше принятого ранее среднего значения $b_{u}=280$ г.у.т./кВт·ч $[25,26]$.

Возросшее количество удельного расхода топлива на выработку электрической энергии необходимо знать для того, чтобы оценить необходимое количество дополнительно сжигаемого топлива в паровом котле. При реализации принципиальной схемы полигенерации, представленной на рис. 1, увеличение расхода топлива позволит оценить минимальное количество (расход) генераторного газа, получаемого при предварительной газификации исходного сырья в аппарате пиролиза и дополнительное количество условного топлива, сжигаемого в котле для получения высокотемпературного водяного пара для газификации.

Экономические индикаторы получения и использования перегретого водяного пара для осуществления процесса Фишера-Тропша

В идеальных условиях при осуществлении процесса газификации состав и количество синтез-газа существенно отличаются в зависимости от характеристик газифицирующего агента (табл. 4).

Для представленных идеальных условий [29]: все реакции (основные и промежуточные) в газогенераторе приводят к образованию следующих компонентов (продуктов) - $\mathrm{CO}, \mathrm{H}_{2}, \mathrm{~N}_{2}$; реакции протекают полностью. В широко используемых в настоящее время процессах газификации применяется паровоздушное и парокислородное дутье (наиболее распространенный процесс) с внешним подводом тепловой энергии или за счет сгорания части газифицируемого материала. Согласно табл. 4, сравнивая парокислородную газификацию и паровую, стоит отметить, что количество произведенного синтез-газа отличается

\begin{tabular}{|c|c|c|c|c|c|}
\hline \multirow{2}{*}{\begin{tabular}{|c|} 
Газифицирующий \\
агент \\
Gasification \\
process (agent)
\end{tabular}} & \multicolumn{3}{|c|}{$\begin{array}{c}\text { Состав газа, \% (об.) } \\
\text { Gas composition, } \\
\% \text { (vol.) }\end{array}$} & \multirow{2}{*}{$\begin{array}{c}V_{g}, \\
\mathrm{~m}^{3} / \mathrm{K} \Gamma \\
\mathrm{m}^{3} / \mathrm{kg}\end{array}$} & \multirow{2}{*}{$\begin{array}{l}Q_{L H V}, \\
\mathrm{MД} / \mathrm{M}^{3} \\
\mathrm{MJ} / \mathrm{m}^{3}\end{array}$} \\
\hline & $\mathrm{CO}$ & $\mathrm{H}_{2}$ & $\mathrm{~N}_{2}$ & & \\
\hline Воздух/Air & 34,7 & - & 65,3 & 5,39 & 4,4 \\
\hline Вода/Water & 50 & 50 & - & 17,7 & 11,77 \\
\hline $\begin{array}{l}\text { Воздух+вода } \\
\text { Air+water }\end{array}$ & 40,3 & 18,2 & 41,5 & 4,63 & 7, \\
\hline $\mathrm{O}_{2}+$ вода $/ \mathrm{O}_{2}$ +water & 68,9 & 31,1 & - & 2,71 & 12,15 \\
\hline
\end{tabular}
более чем в 6,5 раз.
Таблица 4. Состав синтез-газа в идеальном процессе газификаиии [29]

Table 4. Synthesis gas composition in the ideal gasification process [29]

С точки зрения наилучших условий для тепломассообмена между газифицируемой средой и газифицируемым материалом можно выделить кипящий слой и поточный способ газификации. Именно эти условия позволяют получить наибольшее количество синтезгаза с единицы массы газифицируемого топлива. В лабораторных условиях при исследовании различных параметров, влияющих на процесс газификации, образование газа составляет в среднем около $30-40 \%$ от теоретически возможного [30]. Для промышленных поточных газогенераторов при парокислородной газификации угля характерно производство синтезгаза в количестве около $1,8-2$ нм$^{3} /$ кг газифицируемого топлива [31]. Такой расход синтез-газа составляет около $70 \%$ от теоретически возможного (табл. 4). Для известных опытно-промышленных газогенераторов при парокислородной газификации биомассы выход синтез-газа составляет около $1 \mathrm{Hм}^{3} /$ кг [32], или примерно $38 \%$ от теоретически возможного выхода газа. Различие между экспериментальными и теоретическими результатами можно объяснить использованием различного сырья для газификации (уголь и биомасса), а также разными условиями тепломассообмена и гидродинамики в активной зоне газогенератора. Не весь исходный материал может реагировать с газифицирующим агентом, поскольку значительная часть подводимого тепла уходит на протекание различных эндотермических реакций.

Так как паровая бескислородная газификация в чистом виде (с отсутствием любых других газообразных веществ в газифицирующем агенте и без внешнего подвода тепловой энергии) в промышленном масштабе не представлена, примем для дальнейших расчетов выход газа в процентном отношении, аналогичный таковому при парокислородной газификации. В этом случае при сохранении относительных выходов газа с 1 кг газифицируемого материала (табл. 4) можно ожидать около $6,73 \mathrm{HM}^{3} /$ кг газифицируемого материала.

В ранее проводимых экспериментальных исследованиях [29] было установлено, что в зависимости от условий проведения процесса газификации и характеристик газифицируемого материала возможно получить синтез-газ с соотношением около $\mathrm{H}_{2}: \mathrm{CO}=2: 1$. Именно такое соотношение требуется для производства жидких углеводородов по методу ФишераТропша [4]. Поэтому для дальнейшей оценки принято, что синтез-газ может содержать $90 \%$ целевых про- 
дуктов в виде $\mathrm{H}_{2}+\mathrm{CO}$ при их соотношении в смеси $2: 1$ при протекании основной реакции (1).

Сделаем оценку эксплуатационных затрат на производство синтез-газа и синтетического топлива из него при сравнении паровой бескислородной и парокислородной газификации. При оценке эксплуатационных затрат необходимо учитывать следующие параметры: (i) расход и стоимость газифицируемого материала; (ii) количество получаемого синтез-газ; (iii) расход и стоимость перегретого водяного пара; (iv) потребление электричества на выработку кислорода.

Поставленная цель настоящей работы предполагает рассмотрение только процесса производства перегретого водяного пара в условиях полигенерации. Поэтому оценка эксплуатационных затрат будет выполняться с точки зрения газифицирующего агента при сравнении паровой бескислородной газификации и парокислородной. В связи с этим не рассматривается детально процесс ФТ-синтеза и сопутствующие ему эксплуатационные затраты, а также другие затраты, связанные с работой основного оборудования, например затраты электроэнергии на привод насосов и компрессоров.

Эксплуатационные характеристики паровой бескислородной и парокислородной газификации представлены в табл. 5.

В качестве газифицируемого материала для сравнительной оценки принята биомасса в виде древесины. Стоимость воды, электричества, биомассы, кислорода и пара принята на основе данных [33] для Германии (табл. 6). В данном случае выбор страны не имеет значения, так как рассматриваются относительные затраты на два принципиально различных способа газификации по газифицирующему агенту. Расход синтез-газа при осуществлении процесса Фишера-Тропша принят $7000 \mathrm{~m}^{3}$ газа на 1 т получаемых продуктов [34].

Таблица 5. Сравнение процессов газификации

Table 5. Comparison of gasification processes

\begin{tabular}{|c|c|c|c|}
\hline \multirow{2}{*}{ Параметр/Parameter } & \multirow{2}{*}{$\begin{array}{c}\text { Единица } \\
\text { измерения } \\
\text { Unit }\end{array}$} & \multicolumn{2}{|c|}{\begin{tabular}{|c|} 
Вид процесса \\
Type of gasification \\
\end{tabular}} \\
\hline & & $\mathrm{O}_{2}+\mathrm{H}_{2} \mathrm{O}[32]$ & $\mathrm{H}_{2} \mathrm{O}$ \\
\hline \begin{tabular}{|l} 
Расходтоплива \\
(реакция 1) \\
Fuel consumption \\
(Reaction 1)
\end{tabular} & кг $/ \mathrm{kg}$ & 1 & 1 \\
\hline \begin{tabular}{|l} 
Образование \\
синтез-газа \\
Syngas formation \\
\end{tabular} & $\begin{array}{c}\mathrm{m}^{3} \text { (синтез-газа) } / \text { кг } \\
\mathrm{m}^{3} \text { (synt.gas) } / \mathrm{kg}\end{array}$ & 1,04 & 6,73 \\
\hline $\begin{array}{l}\text { Выход продуктов } \\
\text { ФТ-синтеза } \\
\text { FT products formation }\end{array}$ & $\begin{array}{c}\mathrm{m}^{3} \text { (синтез-газа)/кг } \\
\mathrm{m}^{3}(\text { synt.gas }) / \mathrm{kg}\end{array}$ & 7 & 7 \\
\hline \begin{tabular}{|l} 
Расход $\mathrm{H}_{2} \mathrm{O}$ \\
$\mathrm{H}_{2} \mathrm{O}$ consumption \\
\end{tabular} & $\begin{array}{c}\text { кг/м } \mathrm{M}^{3} \text { (синтез-газа) } \\
\mathrm{kg} / \mathrm{m}^{3} \text { (synt.gas) }\end{array}$ & 0,312 & $1,31-3,74$ \\
\hline $\begin{array}{l}\text { Электричество } \\
\text { (производство О } 2) \\
\text { Electricity } \\
\left(\mathrm{O}_{2} \text { production }\right) \\
\end{array}$ & $\begin{array}{c}\text { кВт.ч } / \mathrm{m}^{3} \\
\text { (синтез-газа) } \\
\mathrm{kW} \cdot \mathrm{h} / \mathrm{m}^{3} \text { (synt.gas) }\end{array}$ & 0,231 & 0 \\
\hline
\end{tabular}

Расходные характеристики для парокислородной газификации приняты на основе данных [32]. Затраты на электроэнергию, необходимую для выработки кислорода, приняты на основе усредненных данных для кислородных станций, применяемых для парокислородной газификации угля.

Таблица 6. Стоимость материалов [33]

Table 6. Costs of materials [33]

\begin{tabular}{|l|c|c|}
\hline \multicolumn{1}{|c|}{ Материал/Parameter } & Цена/Price & Ед. измерений/Unit \\
\hline $\begin{array}{l}\text { Биомасса (влажная) } \\
\text { Biomass (wet) }\end{array}$ & 0,0974 & $€ /$ кг/€/kg \\
\hline $\mathrm{H}_{2} \mathrm{O}\left(25\right.$ бар)/H $\mathrm{H}_{2} \mathrm{O}(25$ bar) & 0,026 & $€ /$ кг/€/kg \\
\hline Электричество/Electricity & 0,105 & $€ /(\mathrm{\kappa BT} \cdot \mathrm{q}) / € /(\mathrm{kW} \cdot \mathrm{h})$ \\
\hline
\end{tabular}

По данным табл. 4, 5 определена стоимость эксплуатационных расходов при получении 1 кг жидких продуктов в процессе Фишера-Тропша (табл. 7):

- парокислородная газификация:

Стоимость=расход топлива* цена топлива + +выход синтез-газа* $\mathrm{H}_{2} \mathrm{O}$ расход* цена $\mathrm{H}_{2} \mathrm{O}+$ +выход синтез-газа* щена электричества.

Стоимость $=(1 \cdot 0,974+1,04 \cdot 0,312 \cdot 0,026+1,04 \cdot 0,231 \cdot 0,105) \times$ $\times 1000=131 €$ за $1000 \mathrm{~m}^{3}$ синтез-газа.

- паровая бескислородная газификация:

Стоимость=расход топлива* цена топлива + +расход пара*

Расход топлива ${ }^{*}$ цена топлива $=1 * 0,0974=0,0974 €$. Расход пара* цена пара:

- $A^{d}=70 \%: 1,31 * 0,026 /(6,73 *(1-0,7))=0,016869 €$.

- $A^{d}=10 \%: 3,74 * 0,026 /(6,73 *(1-0,1))=0,016054 €$. После суммирования:

- $A^{d}=70 \%$ - Стоимость $=0,0974+0,016869=0,114269$, или $114,269 €$ за $1000 \mathrm{~m}^{3}$.

- $A^{d}=70 \%$ - Стоимость $=0,0974+0,016054=0,113454$, или $113,454 €$ за $1000 \mathrm{~m}^{3}$.

Среднее значение между $A^{d}=70 \%$ и $A^{d}=10 \%$, соответственно:

$(114,269+113,454) / 2=113,7 €$ за $1000 \mathrm{~m}^{3}$ синтез-газа.

Стоимость жидких продуктов синтеза ФишераТропша:

- парокислородная газификация:

Стоимость $=131 * 7=917 €$ за 1000 кг.

- паровая бескислородная газификация:

Стоимость $=113,7 * 7=795,9 €$ за 1000 кг.

Таблица 7. Стоимость жидких продуктов в процессе Фишера-Тропиа

Table 7. Cost of liquid products in the Fischer-Tropsch process

\begin{tabular}{|c|c|c|}
\hline \multirow[t]{2}{*}{$\begin{array}{l}\text { Категория затрат } \\
\text { Cost category }\end{array}$} & \multicolumn{2}{|c|}{$\begin{array}{c}\text { Вид процесса } \\
\text { газификации } \\
\text { Type of gasification } \\
\text { process }\end{array}$} \\
\hline & $\mathrm{O}_{2}+\mathrm{H}_{2} \mathrm{O}$ & $\mathrm{H}_{2} \mathrm{O}$ \\
\hline $\begin{array}{l}\text { Стоимость синтез-газа, } € / 1000 \mathrm{~m}^{3} \\
\text { Cost of synthesis gas, } € / \mathrm{km}^{3}\end{array}$ & 131 & 113,7 \\
\hline $\begin{array}{l}\text { Стоимость жидких продуктов } \\
\text { ФТ-синтеза, } € / \text { т } \\
\text { Cost of FT-synthesis liquid products, } € / t\end{array}$ & 993,3 & 795,9 \\
\hline
\end{tabular}

Полученные результаты (табл. 7) показывают, что при укрупненной оценке (для идеальных условий) бескислородная паровая газификация оказывается 
намного выгоднее парокислородной технологии. Это связано с тем, что:

- количество синтез-газа при паровой газификации значительно выше, чем при парокислородной (табл. 4, 5);

- при паровой газификации не используется кислород. Таким образом, нет дополнительных установок для производства кислорода, а также затрат электрической энергии.

В табл. 5 относительный выход синтез-газа при сравнении двух технологий газификации принят на основании данных идеального процесса газификации (табл. 4). В действительности относительный расход синтез-газа при сравнении двух процессов окажется значительно ниже. В соответствии с ранее приведенной методикой можно оценить, при каком соотношении выхода газа использование паровой бескислородной технологии газификации становится по затратам сопоставимо с парокислородной (табл. 8).

Таблица 8. Стоимость синтез-газа при различном относительном выходе газа

Table 8. Cost of synthesis gas at different relative gases components

\begin{tabular}{|c|c|c|}
\hline \multirow{2}{*}{$\begin{array}{c}\text { Относительный } \\
\text { выход газа } \\
\begin{array}{c}\text { Relative gases } \\
\text { components }\end{array}\end{array}$} & $\begin{array}{c}\text { Стоимость синтез-газа, } € /\left(10^{3} \cdot \mathrm{m}^{3}\right) \\
\text { при соответствующей технологии } \\
\text { Cost of synthesis gas, } € /\left(10^{3} \cdot \mathrm{m}^{3}\right) \\
\text { with appropriate technology }\end{array}$ \\
\cline { 2 - 3 } & $\mathrm{O}_{2}+\mathrm{H}_{2} \mathrm{O}$ & $\mathrm{H}_{2} \mathrm{O}$ \\
\hline $6,73: 1$ & 131 & 113,7 \\
\hline $5,5: 1$ & 131 & 117,4 \\
\hline $4,5: 1$ & 131 & 121,8 \\
\hline $3,5: 1$ & 131 & 128,8 \\
\hline $2,5: 1$ & 131 & 141,4 \\
\hline $1,5: 1$ & 131 & 170,7 \\
\hline
\end{tabular}

По данным табл. 8 видно, что при соотношении теоретического количества образующегося синтезгаза около 3.5:1 при паровой бескислородной и парокислородной газификации стоимость синтез-газа становится сопоставима.

Расходные характеристики синтез-газа с единицы топлива при любой технологии газификации зависят от степени совершенства конструкции газогенератора. Принятое ранее количество газа, образующееся с единицы массы топлива в процессе парокислородной газификации, может быть увеличено за счет совершенства конструкции газогенератора. При этом стоимость синтез-газа будет снижена за счет большего количества синтез-газа, образующего с единицы массы топлива.

\section{СПИСОК ЛИТЕРАТУРЫ}

1. Gasification of biowaste: a critical review and outlooks / J. Watson, Y. Zhang, B. Si, W-T. Chen, R. de Souza // Renewable and Sustainable Energy Reviews. - 2018. - V. 83. - P. 1-17.

2. Hoya R., Fushimi C. Thermal efficiency of advanced integrated coal gasification combined cycle power generation systems with low-temperature gasifier, gas cleaning and $\mathrm{CO} 2$ capturing units // Fuel Processing Technology. - 2017. - V. 164. - P. 80-91.

3. Techno-economic analysis of a trigeneration system based on biomass gasification / R. Segurado, S. Pereira, D. Correia, M. Costa // Renewable and Sustainable Energy Reviews. - 2019. V. 103. - P. 501-514.

4. Ail S., Dasappa S. Biomass to liquid transportation fuel via Fischer Tropsch synthesis - Technology review and current
Результаты оценки стоимости синтез-газа получены только с учетом эксплуатационных затрат на выработку синтез-газа. При более детальной оценке стоимости синтез-газа необходимо учитывать также затраты на капитальное строительство, оплату труда рабочего персонала и необходимых налогов и отчислений. Технологическое обоснование производства перегретого водяного пара в условиях полигенерации показывает, что при паровой бескислородной технологии отсутствует необходимость в отдельном производстве кислорода, а вместе с этим и в затратах на капитальное строительство и приобретение разнообразных дорогостоящих машин и механизмов.

Детальная оценка затрат на выработку синтез-газа при паровой бескислородной газификации в условиях полигенерации с применением метода ТЕРЕТ [30] будет сделана в отдельной работе.

\section{Выводы}

1. Разработана новая концепция полигенерации для производства электрической и тепловой энергии, а также водяного пара с температурой до $1000{ }^{\circ} \mathrm{C}$ и давлением до 2-3 МПа. Водяной пар с такими параметрами позволяет получать синтез-газ высокого качества с самым высоким содержанием $\mathrm{CO}+\mathrm{H}_{2}$ среди различных технологий газификации.

2. Оценки эксплуатационных расходов производства синтез-газа, полученные по предлагаемой технологии, показывают, что бескислородная паровая газификация может успешно конкурировать с парокислородной технологией при условии получения относительно дешевого водяного пара в условиях полигенерации на тепловых электрических станциях

3. Сравнение эксплуатационных затрат бескислородной паровой технологии получения синтезгаза и парокислородной технологии позволяет утверждать, что бескислородная паровая технология становится более рентабельной при соотношении объемов образующегося газа более 3,5:1.

4. Стоимость синтез-газа при паровой бескислородной газификации может быть примерно на $15 \%$ дешевле по сравнению с парокислородной технологией при укрупненной оценке эксплуатационных затрат.

Исследования выполнены за счет средств гранта Российского научного фонда (проект № 20-79-00012).

scenario // Renewable and Sustainable Energy Reviews. - 2016. V. 58. - P. 267-286.

5. Udomsirichakorn J., Salam P. Review of hydrogen-enriched gas production from steam gasification of biomass: the prospect of CaO-based chemical looping gasification // Renewable and Sustainable Energy Reviews. - 2014. - V. 30. - P. 565-579.

6. Karl J., Pröll T. Steam gasification of biomass in dual fluidized bed gasifiers: a review // Renewable and Sustainable Energy Reviews. - 2018. - V. 98. - P. 64-78.

7. Kalisz S., Pronobis M., Baxter D. Co-firing of biomass wastederived syngas in coal power boiler // Energy. - 2008. - V. 33. P. 1770-1778.

8. Thermodynamic and economic analysis of a partially-underground tower-type boiler design for advanced double reheat power plants / 
G. Xu, C. Xu, Y. Yang, Y. Fang, L. Zhou, Z. Yang // Applied Thermal Engineering. -2015 . - V. 78. - P. 565-575.

9. Пылеугольные энергоблоки на супер- и ультрасверхкритические параметры пара (обзор) / А.Г. Тумановский, А.Л. Шварц, Е.В. Сомова, Э.Х. Вербовецкий, Г.Д. Авруцкий, С.В. Ермакова, Р.Н. Калугин, М.В. Лазарев // Теплоэнергетика. - 2017. № 2. - C. 3-19.

10. ГОСТ 5632-2014 Нержавеющие стали и сплавы коррозионностойкие, жаростойкие и жаропрочные. Марки. - М.: Стандартинформ, 2015. $-54 \mathrm{c}$.

11. Methane steam reforming operation and thermal stability of new porous metal supported tubular palladium composite membranes B. Dittmar, A. Behrens, N. Schödel, M. Rüttinger, Th. Franco, G. Straczewski, R. Dittmeyer // International Journal of Hydrogen Energy. - 2013. - V. 38. - P. 8759-8771.

12. Pashchenko D. First law energy analysis of thermochemical wasteheat recuperation by steam methane reforming // Energy. - 2018. V. 143 . - P. 478-487.

13. Hydrogen and syngas production from sewage sludge via steam gasification / N. Nipattummakul, I.I. Ahmed, S. Kerdsuwan, A.K. Gupta // International Journal of Hydrogen Energy. - 2010. V. 35. - P. $11738-11745$.

14. Экспериментальное исследование процесса горения смесей водород-кислород и метан-кислород в среде слабоперегретого водяного пара / Н.А. Прибатурин, В.А. Федоров, М.В. Алексеев, А.Р. Богомолов, А.Л. Сорокин, С.С. Азиханов, С.А. Шевырев // Теплоэнергетика. 2016. - № 5. - С. 31-36.

15. Makwana J.P., Pandey J., Mishra G. Improving the properties of producer gas using high temperature gasification of rice husk in a pilot scale fluidized bed gasifier (FBG) // Renewable Energy. 2019. - V. 130. - P. 943-951.

16. Advances in mathematical modeling of fluidized bed gasification / C. Loha, S. Gu, J. De Wilde, P. Mahanta, P.K. Chatterjee // Renewable and Sustainable Energy Reviews. - 2014. - V. 40. P. 688-715.

17. Hossain M.K., Strezov V., Nelson P.F. Thermal characterization of the products of wastewater sludge pyrolysis // Journal of Analytical and Applied Pyrolysis. - 2009. - V. 85. - P. 442-446.

18. Результаты опытно-эксплуатационного сжигания водоугольного топлива в водогрейном котле малой мощности / С.В. Алексеенко, Л.И. Мальцев, А.Р. Богомолов, М.Ю. Чернецкий, И.В. Кравченко, А.И. Кравченко, Д.А. Лапин, С.А. Шевырёв, С.Ю. Лырщиков // Известия ТПУ. Инжиниринг георесурсов. - 2017. - Т. 328. - № 12. - С. 16-28.

19. Богомолов А.Р., Шевырёв С.А., Алексеев М.В. Перспективы высокотемпературной газификации угля и шлама // Теплоэнергетика. - 2013. - № 2. - С. 77-80.

20. Watanabe H., Otaka M. Numerical simulation of coal gasification in entrained flow coal gasifier // Fuel. - 2006. - V. 85 . - P. 1935-1943.
21. Progress in biofuel production from gasification / V.S. Sikarwar, M. Zhao, P.S. Fennell, N. Shah, E.J. Anthony // Progress in Energy and Combustion Science. - 2017. - V. 61. - P. 189-248.

22. Shilyaev M.I., Afanas'ev Y.O., Bogomolov A.R. Calculating the solid fuel combustion process in a cyclone reactor // Thermal Engineering. - 2011. - V. 58. - P. 981-987.

23. One-dimensional model of heat-recovery, non-recovery coke ovens. P. II: Coking-bed sub-model / R. Buczynski, R. Weber, R. Kim, P. Schwöppe // Fuel. - 2016. - V. 181. - P. 1115-1131

24. Behbahaninia A., Ramezani S., Lotfi Hejrandoost M. A loss method for exergy auditing of steam boilers // Energy. - 2017. V. $140 .-$ P. $253-260$.

25. Numerical investigation of oxy-fuel combustion in $700{ }^{\circ} \mathrm{C}$-ultrasupercritical boiler / X. Ge, J. Dong, H. Fan, Z. Zhang, X. Shang, X. Hu, J. Zhang // Fuel. - 2017. - V. 207. - P. 602-614.

26. Тумановский А.Г. Перспективы развития угольных ТЭС России // Теплоэнергетика. - 2017. - № 6. - С. 3-13.

27. Impact of power station capacities and sizes of solar field on the performance of solar aided power generation / C. Huang, H. Hou, E. Hu, M. Liang, Y. Yang // Energy. - 2017. - V. 139. - P. 667-679.

28. Behar O. Solar thermal power plants - a review of configurations and performance comparison // Renewable and Sustainable Energy Reviews. - 2018. - V. 92. - P. 608-627.

29. Shevyrev S., Bogomolov A., Alekssev M. Prospects for production of synthetic liquid fuel from low-grade coal // EPJ Web of Conferences. - 2015. - V. 82. - P. 01033.

30. Syngas production by chemical looping gasification of biomass with steam and $\mathrm{CaO}$ additive / Y. Wu, Y. Liao, G. Liu, X. Ma // International Journal of Hydrogen Energy. - 2018. - V. 43. P. 19375-19383.

31. Qin S., Chang S., Yao Q. Modeling, thermodynamic and technoeconomic analysis of coal-to-liquids process with different entrained flow coal gasifiers // Applied Energy. - 2018. - V. 229. P. 413-432.

32. Steam/oxygen biomass gasification at pilot scale in an internally circulating bubbling fluidized bed reactor / D. Barisano, G. Canneto, F. Nanna, E. Alvino, G. Pinto, A. Villone, M. Carnevale, V. Valerio, A. Battafarano, G. Braccio // Fuel Processing Technology. - 2016. - V. 141. - P. 74-81.

33. A standardized methodology for the techno-economic evaluation of alternative fuels - a case study / F.G. Albrecht, D.H. König, N. Baucks, R.-U. Dietrich // Fuel. - 2017. - V. 194. - P. 511-526.

34. Mrakin A.N., Akimova G.A. Complex analysis of the efficiency of plants for the thermochemical conversion of solid fuel // Solid Fuel Chemistry. - 2015. - V. 49. - P. 261-265.

Поступила 09.12.2020 г.

\section{Информация об авторах}

Шевырёв С.A., кандидат технических наук, доцент кафедры теплоэнергетики Института энергетики Кузбасского государственного технического университета имени Т.Ф. Горбачева.

Стрижак П.А., доктор физико-математических наук, профессор НОЦ И.Н. Бутакова Национального исследовательского Томского политехнического университета.

Ральф-Юве Дитрих, профессор, Немецкий космический центр, Институт инженерной термодинамики.

Богомолов A.P., доктор технических наук, ведущий научный сотрудник лаборатории проблем тепломассопереноса Института теплофизики им. С.С. Кутателадзе СО РАН. 


\title{
OXYGEN-FREE STEAM GASIFICATION UNDER POLYGENERATION
}

\section{Sergey A. Shevyrev ${ }^{1}$,} ssa.pmahp@kuzstu.ru

\section{Pavel A. Strizhak} pavelspa@tpu.ru

Ralph-Uwe Dietrich ${ }^{3}$, ralph-uwe.dietrich@dlr.de

\author{
Aleksandr R. Bogomolov 4 \\ barom@kuzstu.ru
}

1 T.F. Gorbachev Kuzbass State Technical University, 28, Vesennyaya street, Kemerovo, 650000, Russia.

2 National Research Tomsk Polytechnic University, 30, Lenin avenue, Tomsk, 634050, Russia.

${ }^{3}$ German Aerospace Center, Institute of Engineering Thermodynamics, Energy System Integration, 38-40, Pfaffenwaldring, Stuttgart, 70569, Germany.

4 Kutateladze Institute of Thermophysics SB RAS,

1, Ac. Lavrentiev avenue, Novosibirsk, 630090, Russia.

The relevance of the research is associated with the prospects for solid fuel deep processing with an unconventional method of producing superheated water vapor at thermal power plants with oxygen-free steam gasification. This will make it possible to create highly efficient energy technology enterprises at thermal power plants with the production of not only thermal and electrical energy, but also a variety of chemicals, in particular hydrogen and Fischer-Tropsch synthesis products.

The main aim of the research is to substantiate the possibility and prospects of the implementation of steam oxygen-free gasification at thermal power plants in comparison with the widely used process of steam-oxygen gasification; to compare the steam-oxygen and steam oxygen-free gasification in terms of the cost of chemicals obtained from synthesis gas in the Fischer-Tropsch process.

Objects: oxygen-free steam gasification of solid fuels under polygeneration conditions; method of producing superheated water vapor at thermal power plants for oxygen-free steam gasification.

Methods: thermodynamic analysis of the operation of thermal power plants with integrated gasification process; analytical calculation of the oxygen-free steam gasification and its comparison with the steam-oxygen gasification; simplified calculation of the cost of FischerTropsch synthesis products in comparison with steam oxygen-free gasification and steam-oxygen gasification.

Results. This paper presents a new concept of polygeneration using oxygen-free steam gasification under conditions of steam production at thermal power plants. The new polygeneration concept assumes the production of water vapor with high temperature (up to $1000^{\circ} \mathrm{C}$ ) and pressure (up to 2-3 MPa) with a high flow rate for the implementation of oxygen-free steam gasification of solid fuels. The concept is based on the thermodynamic justification of the operation of thermal power plants with a traditional steam-power cycle and the redistribution of material flows between a steam boiler and a steam turbine. A simplified economic assessment was made to calculate the price of syngas produced by steam oxygen-free gasification. It is shown that the production of synthesis gas by oxygen-free steam gasification in the new concept can be $15 \%$ cheaper than with the traditional steam-oxygen technology. This can be achieved if the ratio of the generated gas in steam oxygen-free gasification and steam-oxygen technologies is more than 3,5:1 respectively.

Key words:

High temperature water vapor, oxygen-free gasification, renewable resources, polygeneration, Fischer-Tropsch synthesis.

This work was supported by the Russian Science Foundation (project no. 20-79-00012).

\section{Nomenclature}

- $\quad T$ - temperature, ${ }^{\circ} \mathrm{C}$;

- $P$ - pressure, $\mathrm{Pa}$;

- $\mathrm{S}$ - entropy, $\mathrm{kJ} /(\mathrm{kg} \cdot \mathrm{K})$;

- $K$ - critical point for water;

- $G_{e x}-$ feed water flow to the steam boiler, $\mathrm{kg} / \mathrm{s}$;

- $G_{w v}$ - consumption of superheated steam coming from the steam turbine to the boiler for additional superheating, $\mathrm{kg} / \mathrm{s}$;

- $\Delta H$ - thermal effect of a chemical reaction, $\mathrm{J} / \mathrm{kg}$;
- $c_{a}$ - ash heat capacity, $\mathrm{kJ} /(\mathrm{kg} \cdot \mathrm{K})$;

- $c_{c}$ - carbon heat capacity, $\mathrm{kJ} /(\mathrm{kg} \cdot \mathrm{K})$;

- $c_{\text {aav }}$ - average ash heat capacity, $\mathrm{kJ} /(\mathrm{kg} \cdot \mathrm{K})$;

- $c_{c a v}$ - average carbon heat capacity, $\mathrm{kJ} /(\mathrm{kg} \cdot \mathrm{K})$;

- $c$ - char heat capacity, $\mathrm{kJ} /(\mathrm{kg} \cdot \mathrm{K})$;

- $i_{s}$ - specific enthalpy of superheated steam at appropriate pressure and temperature, $\mathrm{kJ} / \mathrm{kg}$;

- $A^{d}$ - char ash content, \% wt;

- $G_{s s}$ - superheated water vapor consumption for gasification, $\mathrm{kg} / \mathrm{s}$; 
- $Q_{s s}$ - heat flux of superheated steam fed to gasification, W;

- $G_{g m}$ - consumption of gasified material in the gas generator, $\mathrm{kg} / \mathrm{s}$;

- $G_{s t}-$ consumption of superheated steam from the steam turbine for gasification, $\mathrm{kg} / \mathrm{s}$;

- $Q_{w}$ - heat flux to feed water heating, W;

- $i_{220}^{15.5}$ - feed water enthalpy at a temperature of $220{ }^{\circ} \mathrm{C}$ and a pressure of $15,5 \mathrm{MPa}, \mathrm{kJ} / \mathrm{kg}$;

- $\quad i_{10}^{0.1}$ - feed water enthalpy at $10{ }^{\circ} \mathrm{C}$ and pressure 0,1 $\mathrm{MPa}, \mathrm{kJ} / \mathrm{kg}$;

- $Q_{s t}$ - heat flux required for superheating of steam supplied for gasification, W;

- $i_{1000}^{2}-$ enthalpy of superheated steam at a temperature of $1000{ }^{\circ} \mathrm{C}$ and a pressure of $2 \mathrm{MPa}, \mathrm{kJ} / \mathrm{kg}$;

- $\quad i_{250}^{2}-$ enthalpy of superheated steam at a temperature of $250^{\circ} \mathrm{C}$ and a pressure of $2 \mathrm{MPa}, \mathrm{kJ} / \mathrm{kg}$;

- $Q_{\text {e.f. }}$ - calorific value of equivalent fuel, $29,308 \mathrm{MJ} / \mathrm{kg}$;

\section{REFERENCES}

1. Watson J., Zhang Y., Si B., Chen W-T., de Souza R. Gasification of biowaste: a critical review and outlooks. Renewable and Sustainable Energy Reviews, 2018, vol. 83, pp. 1-17.

2. Hoya R., Fushimi C. Thermal efficiency of advanced integrated coal gasification combined cycle power generation systems with low-temperature gasifier, gas cleaning and $\mathrm{CO}_{2}$ capturing units. Fuel Processing Technology, 2017, vol. 164, pp. 80-91.

3. Segurado R., Pereira S., Correia D., Costa M. Techno-economic analysis of a trigeneration system based on biomass gasification Renewable and Sustainable Energy Reviews, 2019, vol. 103, pp. 501-514.

4. Ail S., Dasappa S. Biomass to liquid transportation fuel via Fischer Tropsch synthesis - Technology review and current scenario. Renewable and Sustainable Energy Reviews, 2016, vol. 58, pp. 267-286.

5. Udomsirichakorn J., Salam P.A. Review of hydrogen-enriched gas production from steam gasification of biomass: the prospect of CaO-based chemical looping gasification. Renewable and Sustainable Energy Reviews, 2014, vol. 30, pp. 565-579.

6. Karl J., Pröll T. Steam gasification of biomass in dual fluidized bed gasifiers: a review. Renewable and Sustainable Energy Reviews, 2018, vol. 98, pp. 64-78.

7. Kalisz S., Pronobis M., Baxter D. Co-firing of biomass wastederived syngas in coal power boiler. Energy, 2008, vol. 33, pp. $1770-1778$

8. Xu G., Xu C., Yang Y., Fang Y., Zhou L., Yang Z. Thermodynamic and economic analysis of a partially-underground towertype boiler design for advanced double reheat power plants. Applied Thermal Engineering, 2015, vol. 78, pp. 565-575.

9. Tumanovskii A.G., Shvarts A.L., Somova E.V., Verbovetskii E.Kh., Avrutskii G.D., Ermakova S.V., Kalugin R.N., Lazarev M.V. Review of the coal-fired, over-supercritical and ultra-supercritical steam power plants. Thermal Engineering, 2017, vol. 64, pp. 83-96.

10. GOST 5632-2014 Nerzhaveyushchie stali $i$ splavy korrozionnostoykie, zharostoykie $i$ zharoprochnye. Marki [State Standard 5632-2014. Stainless steels and corrosion resisting, heat-resisting and creep resisting alloys. Grades]. Moscow, Standartinform Publ., 2015. 54 p. ГОСТ

11. Dittmar B., Behrens A., Schödel N., Rüttinger M., Franco Th., Straczewski G., Dittmeyer R. Methane steam reforming operation and thermal stability of new porous metal supported tubular palladium composite membranes. International Journal of Hydrogen Energy, 2013, vol. 38, pp. 8759-8771.

12. Pashchenko D. First law energy analysis of thermochemical wasteheat recuperation by steam methane reforming. Energy, 2018, vol. 143 , pp. $478-487$
- $G_{f}$ - fuel consumption for feed water heating, $\mathrm{kg} / \mathrm{s}$;

- $G_{b . f .}$ - extra fuel consumption in a steam boiler, $\mathrm{kg} / \mathrm{s}$;

- $B_{u}$ - fuel consumption in the steam boiler, $\mathrm{kg} / \mathrm{s}$;

- $b_{u}$ - specific consumption of reference fuel for the generation of electric energy, $\mathrm{g} /\left(\mathrm{kW}_{\mathrm{e}} \cdot \mathrm{h}\right)$

- $N_{e l}$ - turbine electric power, MW;

- $Q_{\text {st.b }}$ - heat load (power) of the steam boiler, MW;

- $q_{t u}-$ specific heat consumption for electricity generation, $\mathrm{MJ} /(\mathrm{kW} \cdot \mathrm{h})$

- $\eta_{p}$ - efficiency of steam transportation from the boiler to the steam turbine, $\%$;

- $\eta_{s t . b}$ - steam boiler efficiency, \%;

- $\eta_{p s}$ - thermal power plant efficiency, \%;

- $V_{g}$ - gas formation in an ideal gasification process, $\mathrm{m}^{3} / \mathrm{kg}$

- $Q_{L H V}-$ net calorific value of gas, $\mathrm{MJ} / \mathrm{kg}$;

- FT - Fischer-Tropsch chemical synthesis;

- TEPET - Techno-Economic Process Evaluation Tool.

13. Nipattummakul N., Ahmed II., Kerdsuwan S., Gupta A.K. Hydrogen and syngas production from sewage sludge via steam gasification. International Journal of Hydrogen Energy, 2010, vol. 35, pp. 11738-11745.

14. Pribaturin N.A., Fedorov V.A., Alekseev M.V., Bogomolov A.R., Sorokin A.L., Azikhanov S.S., Shevyrev S.A. Experimental investigation on combustion of hydrogen-oxygen and methane-oxygen mixtures in the medium of low-superheated steam. Thermal Engineering, 2016, vol. 63, pp. 336-341.

15. Makwana J.P., Pandey J., Mishra G. Improving the properties of producer gas using high temperature gasification of rice husk in a pilot scale fluidized bed gasifier (FBG). Renewable Energy, 2019, vol. 130, pp. 943-951.

16. Loha C., Gu S., De Wilde J., Mahanta P., Chatterjee P.K. Advances in mathematical modeling of fluidized bed gasification. Renewable and Sustainable Energy Reviews, 2014, vol. 40, pp. 688-715.

17. Hossain M.K., Strezov V., Nelson P.F. Thermal characterisation of the products of wastewater sludge pyrolysis. Journal of Analytical and Applied Pyrolysis, 2009, vol. 85, pp. 442-446.

18. Alekseenko S.V., Maltsev L.I., Bogomolov A.R., Chernetskiy M.Yu., Kravchenko I.V., Kravchenko A.I., Lapin D.A., Shevyrev S.A., Lyrshchikov S.Yu. Results of pilot-operating combustion of coal-water fuel in a low-capacity hot water boiler. Bulletin of the Tomsk Polytechnic University, Geo Assets Engineering, 2017,vol. 328, pp. 16-28. In Rus.

19. Bogomolov A.R., Shevyrev S.A., Alekseev M.V. Prospects for high-temperature gasification of coal and sludge. Thermal Engineering, 2013, vol. 60, pp. 153-156.

20. Watanabe H., Otaka M. Numerical simulation of coal gasification in entrained flow coal gasifier. Fuel, 2006,vol. 85, pp. 1935-1943.

21. Sikarwar V.S., Zhao M., Fennell P.S., Shah N., Anthony E.J. Progress in biofuel production from gasification. Progress in Energy and Combustion Science, 2017, vol. 61, pp. 189-248.

22. Shilyaev M.I., Afanas'ev Y.O., Bogomolov A.R. Calculating the solid fuel combustion process in a cyclone reactor. Thermal Engineering, 2011, vol. 58, pp. 981-987.

23. Buczynski R., Weber R., Kim R., SchwöppeP. One-dimensional model of heat-recovery, non-recovery coke ovens. P. II: Cokingbed sub-model. Fuel, 2016, vol. 181, pp. 1115-1131.

24. Behbahaninia A., Ramezani S., Lotfi Hejrandoost M. A loss method for exergy auditing of steam boilers. Energy, 2017, vol. 140, pp. 253-260.

25. Ge X., Dong J., Fan H., Zhang Z., Shang X., Hu X., Zhang J. Numerical investigation of oxy-fuel combustion in $700{ }^{\circ} \mathrm{C}$-ultrasupercritical boiler. Fuel, 2017, vol. 207, pp. 602-614.

26. Tumanovskii A.G. Prospects for the development of coal-steam plants in Russia. Thermal Engineering, 2017, vol. 64, pp. 399-407.

27. Huang C., Hou H., Hu E., Liang M., Yang Y. Impact of power station capacities and sizes of solar field on the performance of solar aided power generation. Energy, 2017, vol. 139, pp. 667-679. 
28. Behar O. Solar thermal power plants - a review of configurations and performance comparison. Renewable and Sustainable Energy Reviews, 2018, vol. 92, pp. 608-627.

29. Shevyrev S., Bogomolov A., Alekssev M. Prospects for production of synthetic liquid fuel from low-grade coal. EPJ Web of Conferences, 2015, vol. 82, pp. 01033.

30. Wu Y., Liao Y., Liu G., Ma X. Syngas production by chemical looping gasification of biomass with steam and $\mathrm{CaO}$ additive. $\mathrm{In}$ ternational Journal of Hydrogen Energy, 2018, vol. 43, pp. 19375-19383.

31. Qin S., Chang S., Yao Q. Modeling, thermodynamic and technoeconomic analysis of coal-to-liquids process with different entrained flow coal gasifiers. Applied Energy, 2018, vol. 229, pp. 413-432.
32. Barisano D., Canneto G., Nanna F., Alvino E., Pinto G., Villone A., Carnevale M., Valerio V., Battafarano A., Braccio G. Steam/oxygen biomass gasification at pilot scale in an internally circulating bubbling fluidized bed reactor. Fuel Processing Technology, 2016, vol. 141, pp. 74-81.

33. Albrecht F.G., König D.H., Baucks N., Dietrich R-U. A standardized methodology for the techno-economic evaluation of alternative fuels - a case study. Fuel, 2017, vol. 194, pp. 511-526.

34. Mrakin A.N., Akimova G.A. Complex analysis of the efficiency of plants for the thermochemical conversion of solid fuel. Solid Fuel Chemistry, 2015, vol. 49, pp. 261-265.

Received: 9 December 2020.

\section{Information about the authors}

Sergey A. Shevyrev, Cand. Sc., associate professor, T.F. Gorbachev Kuzbass State Technical University.

Pavel A. Strizhak, Dr. Sc., professor, National Research Tomsk Polytechnic University.

Ralph-Uwe Dietrich, Dr.-Ing., German Aerospace Center.

Aleksandr R. Bogomolov, Dr. Sc., leading researcher, Kutateladze Institute of Thermophysics SB RAS. 